Review Article

\title{
Mucocutaneous Involvement in Behçet's Disease: How Systemic Treatment Has Changed in the Last Decades and Future Perspectives
}

\author{
Cinzia Rotondo, ${ }^{1}$ Giuseppe Lopalco, ${ }^{1}$ Florenzo Iannone, ${ }^{1}$ Antonio Vitale, ${ }^{2}$ \\ Rosaria Talarico, ${ }^{3}$ Mauro Galeazzi, ${ }^{2}$ Giovanni Lapadula, ${ }^{1}$ and Luca Cantarini ${ }^{2}$ \\ ${ }^{1}$ Interdisciplinary Department of Medicine, University of Bari, Piazza Giulio Cesare 11, 70124 Bari, Italy \\ ${ }^{2}$ Research Center of Systemic Autoimmune and Autoinflammatory Diseases, University of Siena, Viale Bracci 1, 53100 Siena, Italy \\ ${ }^{3}$ Rheumatology Unit, Department of Clinical and Experimental Medicine, University of Pisa, Via Roma 67, 56126 Pisa, Italy \\ Correspondence should be addressed to Luca Cantarini; cantariniluca@hotmail.com
}

Received 12 April 2015; Accepted 19 May 2015

Academic Editor: Julio Galvez

Copyright (C) 2015 Cinzia Rotondo et al. This is an open access article distributed under the Creative Commons Attribution License, which permits unrestricted use, distribution, and reproduction in any medium, provided the original work is properly cited.

Behçet's disease (BD) is a multisystemic disorder of unknown etiology characterized by the "triple symptom complex" consisting of recurrent oral aphthosis, genital ulcers, and chronic relapsing bilateral uveitis. Recurrent mucocutaneous lesions are generally considered the hallmark of the disease, being the most common symptoms presenting at the onset of disease. Although the improvement of knowledge about the pathogenetic mechanism added important changes in the treatment management of $\mathrm{BD}$ clinical manifestations, thus avoiding the appearance of serious life-threatening complications which are disease related, the mucocutaneous lesions are still the most nagging clinical manifestations to be treated. In this work we reviewed the current state of knowledge regarding the therapeutic approaches for mucocutaneous lesions of BD mainly based on controlled studies to provide a rational framework for selecting the appropriate therapy for treating these troublesome features of the disease.

\section{Introduction}

Behçet's disease $(\mathrm{BD})$ is an inflammatory disorder of undetermined aetiology, which is recently and unanimously recognized as both autoimmune and autoinflammatory disease [1]. Indeed, many of its classical manifestations and the characteristics of the recurrent course overlap with those of monogenic autoinflammatory disorders [2-5].

It is hypothesized that the main pathogenetic elements are represented by genetic predisposition, mainly HLA dependent, and environmental factors. Furthermore, it is believed that a misdirected immune response, triggered by some microbial agents (as herpes simplex virus-1 and Streptococcus sanguinis), could play a pivotal role in the pathogenesis of $\mathrm{BD}$ [6]. In this regard, the abnormal activation of either innate and adaptive immunity with consequent interaction of both $\mathrm{T}$ lymphocytes (mainly Thl and Th17 phenotype) and activated neutrophils would seem to be involved in the disease onset [7-9]. Many cytokines may contribute to the pathological mechanism of $\mathrm{BD}[6,10-12]$; high sera title of tumor necrosis factor- (TNF-) alpha is found in patients with active BD [13] and the role of TNF-alpha inhibition in the pathogenesis of ocular inflammation was described in mice models [14]. Interleukin- (IL-) 6 has been demonstrated to be related to $\mathrm{BD}$ activity and central nervous system involvement, as confirmed by its high levels in CSF [15]. Recent studies have suggested a role of IL-1 in BD; actually IL-1 high title is found in sera [16] and synovial fluid of BD patients [17]. Indeed IL1 may play a key role in the pathogenesis of ocular [18] and mucocutaneous involvement [19], although in the latter case evidence from literature is not entirely encouraging [20-23].

$\mathrm{BD}$ is clinically characterised by multiple organ involvement, in particular by the "triple symptom complex," consisting of recurrent oral aphthosis, genital ulcers, and recurrent 
TABLE 1: Brief summary of the main clinical manifestations of Behçet's disease.

\begin{tabular}{|c|c|c|}
\hline Organ involvements & Clinical manifestations & Recommended treatment \\
\hline Mucocutaneous & $\begin{array}{l}\text { Oral aphthae, genital ulcers, pseudofolliculitis, } \\
\text { papulopustular lesions, erythema nodosum-like lesions, } \\
\text { and pathergy reaction }\end{array}$ & $\begin{array}{l}\text { Colchicine, azathioprine, interferon- } \alpha \text {, and TNF- } \alpha \\
\text { antagonist }\end{array}$ \\
\hline Eye disease & $\begin{array}{l}\text { Recurrent bilateral uveitis (anterior segment, posterior } \\
\text { segment, or both), retinal vasculitis, retinal vein } \\
\text { occlusion, and optic neuritis }\end{array}$ & $\begin{array}{l}\text { Azathioprine, local or systemic corticosteroids, } \\
\text { cyclosporine, infliximab (in combination with } \\
\text { azathioprine and corticosteroids), and interferon- } \alpha \text {. }\end{array}$ \\
\hline Gastrointestinal tract & $\begin{array}{l}\text { Anorexia, vomiting, dyspepsia, diarrhea, abdominal } \\
\text { pain, ulcers, ischemic perforation, thrombosis in the } \\
\text { terminal ileum, ileocecal region, and colon }\end{array}$ & $\begin{array}{l}\text { Sulfasalazine, corticosteroids, azathioprine, TNF- } \alpha \\
\text { antagonista, and thalidomide. In emergency surgical } \\
\text { procedures are required such as ileocolectomy or } \\
\text { hemicolectomy }\end{array}$ \\
\hline $\begin{array}{l}\text { Musculoskeletal } \\
\text { system }\end{array}$ & $\begin{array}{l}\text { Nonerosive arthritis, nondeforming oligoarthritis, back } \\
\text { pain, and sacroiliitis }\end{array}$ & $\begin{array}{l}\text { Colchicine, interferon- } \alpha \text {, azathioprine, and TNF- } \alpha \\
\text { antagonists }\end{array}$ \\
\hline $\begin{array}{l}\text { Cardiovascular } \\
\text { system }\end{array}$ & $\begin{array}{l}\text { Vasculitis, superficial thrombophlebitis, deep vein } \\
\text { thrombosis, dural sinus thrombosis, occlusion of } \\
\text { suprahepatic veins, pericarditis, myocarditis, } \\
\text { endocarditis, intracardiac thrombosis, coronary } \\
\text { vasculitis, and ventricular aneurysm }\end{array}$ & $\begin{array}{l}\text { Corticosteroids, azathioprine, cyclosporine, and } \\
\text { cyclophosphamide }\end{array}$ \\
\hline $\begin{array}{l}\text { Central nervous } \\
\text { system }\end{array}$ & $\begin{array}{l}\text { Severe headache and pyramidal and extrapyramidal } \\
\text { symptom (seizures, hemiplegia, and cranial nerve } \\
\text { palsies) } \\
\text { Central nervous system: focal necrotic cerebral lesions, } \\
\text { vascular thrombosis, arterial vasculitis, and aseptic } \\
\text { meningoencephalitis } \\
\text { Peripheral nervous system: peripheral neuropathies and } \\
\text { multiplex mononeuritis }\end{array}$ & $\begin{array}{l}\text { Corticosteroids, interferon- } \alpha \text {, azathioprine, } \\
\text { cyclophosphamide, methotrexate, and TNF- } \alpha \\
\text { antagonists. }\end{array}$ \\
\hline
\end{tabular}

bilateral uveitis. Besides this classical clinical trial, BD recognizes also other organ involvements, as summarised in Table 1 [24-28].

Mucocutaneous lesions are the earliest and the most frequent manifestations of BD which may anticipate by many years other typical clinical symptoms. The most common mucocutaneous lesions are oral aphthae (OA), which are included in the BD classification criteria. OA are characterized by recurrent and painful oral mucosa ulcerations. They manifest themselves, more frequently as minor aphthous ulcers ( $<10 \mathrm{~mm}$ in diameter) or, less frequently, as major ulcers $(>10 \mathrm{~mm}$ in diameter, deeper and more painful than minor ulcers) or also as herpetiform ulcers (numerous, shallow, and small-pinpoint ulcers occurring in coalescing clusters). The genital ulcers (GU) are the second main symptom reported in the literature. They are similar in appearance and course to OA. The most frequently involved body areas are the scrotum in males and the major and minor labia in females. Cutaneous lesions, important characteristics of the disease, have been described as a major criterion for the classification. They mainly include erythema nodosum-like lesions, papulopustular lesions (sterile folliculitis-like lesions on an erythematous base), superficial thrombophlebitis, extragenital ulceration, and other cutaneous vasculitic lesions [29]. Skin pathergy reaction represents the unifying feature of the typical BD inflammation and is characterised by the presence of an abnormal skin reaction to traumatic insults or different types of inflammatory stimuli [30]. Moreover, pathergy phenomenon has no association with specific organ involvement or disease activity and is not only restricted to the skin [31].

The mucocutaneous manifestations are characterized by recurrent relapses; they usually have moderate to long-term course and their spontaneous resolution is rarely described. A wide number of conventional immunosuppressive drugs could be used to treat these lesions, but several failures, with lesion relapses, are commonly reported. The concomitant BD manifestations often drive the therapy management [32].

Herewith, we provide a review of the literature published on treatment strategies for mucocutaneous BD involvement, focusing on how treatment has changed in the last decades and on possible future perspectives.

Hints from Treatment Guidelines. In 2008 the EULAR treatment recommendations were published; they suggested treating skin and mucosa involvement both depending on the perceived severity and shared doctor-patient decision and according to dominant or concomitant manifestations. Topical measures (i.e., local corticosteroids) should be the firstline treatment for isolated oral and genital ulcers and acnelike lesions. Colchicine should be preferred when the dominant lesion is erythema nodosum. Azathioprine, INF-alpha, and TNF-alpha antagonist may be considered in resistant cases [32]. Some immunomodulator drugs, as tocilizumab and mycophenolate mofetil, have failed to reach a clinical improvement in the mucocutaneous lesions [28]. New drugs as apremilast seem to be effective in the treatment of oral and genital aphthosis [33]. Further studies may be necessary 
to prove the drug efficacy. The improvement of knowledge about the pathogenetic mechanism could add important changes in the treatment management of the BD clinical manifestation.

\section{Literature Review}

An electronic literature search was conducted using SCHOLAR, SCOPUS, and PUBMED. Case reports, open and double-blind trials, and cohort studies published up until 2015 were evaluated (Table 2). With regard to the drugs under clinical experimentation, the "clinicaltrials.gov" web site was consulted.

2.1. Past Decades. A wide range of drugs is available for treating mucocutaneous lesions in $\mathrm{BD}$. In the past decades, traditional immunosuppressive agents were largely used to reduce the ulcers disability, but some contrasting results were observed, particularly in terms of maintaining remission effectiveness.

2.1.1. Azathioprine. Azathioprine seems to be effective in controlling the progression of $\mathrm{BD}$, especially in most critical manifestations, such as eye diseases. IARCT described a favourable effect on mucocutaneous lesions, as proven by statistically significant reductions in the frequency of oral and genital ulcerations; in particular, preventive effects were observed for GU and a healing improvement for OA [34].

2.1.2. Colchicine and Antibiotics. It is well known that colchicine is recommended as a first-line therapy in erythema nodosum-like lesions in BD [32]. The effects on erythema nodosum were described in three double-blind, placebocontrolled trials [35-37]. In a double-blind trial the colchicine effects on reducing of GU were proven. No effects on OA and folliculitis were observed (the dose of colchicine was adjusted according to body weight) [36]. On the contrary, in another double-blind controlled crossover trial, OA, GU, and pseudofolliculitis improvements were described [37]. Two prospective studies, evaluating the association of colchicine and benzathine penicillin, have described the decrease in the frequency and duration of OA and erythema nodosum and an improvement of the frequency of GU $[38,39]$. The beneficial effects of antibacterial therapy may be supported by the hypothesized role of streptococci in $\mathrm{BD}$ [1].

2.1.3. Azithromycin. Azithromycin is a macrolide antibiotic characterized by wide spectrum of action. Its immunomodulatory effects are supposed [40]. The use of azithromycin in $\mathrm{BD}$ is based on previous hypothesis that Streptococcus sanguinis play a main role in pathogenesis of $\mathrm{BD}$ [41]. Two case series $[42,43]$ described the effectiveness of azithromycin in decreasing folliculitis and in fastening the healing time of oral ulcers.

2.1.4. Minocycline. Minocycline is described to decrease the frequency of the OA, erythema nodosum lesions, and papulopustular lesions in an open study [44].
2.1.5. Thalidomide. Despite failing in the treatment of eye involvement, one RCT [45], a pilot study [46], and three open studies [47-49] have demonstrated thalidomide effectiveness in the treatment of $\mathrm{OA}, \mathrm{GU}$, and papulopustular lesions, while an increase in the frequency of nodular lesion was reported. However, it is well known that thalidomide is associated with severe adverse events and birth defects, whereby its use is limited.

2.1.6. Cyclosporine. Cyclosporine, a synthesis and release inhibitor of the IL-1 and IL-2, is frequently used in the treatment of eye involvements in $\mathrm{BD}$, but just few evidences are described about mucocutaneous lesions. A double-blind trial [50], a controlled study [51], and an open study [52] showed that cyclosporine is effective in the GU and dermal lesion. The administrated dose is ranged from 5 to $10 \mathrm{mg} / \mathrm{kg} / \mathrm{day}$.

2.1.7. Dapsone. Dapsone has proven to inhibit the chemotaxis of neutrophils [53]. A dose of $100 \mathrm{mg}$ per day has been demonstrated to be very effective in healing the mucocutaneous lesions; as evidenced in an open study [54] and in a double-blind placebo-controlled clinical trial, dapsone showed relevant effects by decreasing the frequency and the duration of $\mathrm{OA}$ and the number and the frequency of GU [55]. No data are available regarding the duration of remission over time.

2.1.8. Rebamipide. Rebamipide, a well-known gastric mucoprotective agent, used to treat gastritis and gastric ulcer in Japan, is observed to improve the aphthae count and to relieve the pain secondary to oral ulcers in a double placebo-controlled study. The authors conclude that it could be recommended as a long-term treatment for recurrent OA, also in association with other indicated drugs [56].

2.1.9. Interferon-Alpha. Interferon-alpha, a large family of glycoproteins, seems to provide a cellular response to the foreign constituents of microbes, tumor, and antigens and is used in the treatment of several diseases. Although its mechanism of action is not well defined, INF-alpha seems to restore the low natural killer cell activity in patients with $\mathrm{BD}$ to a near normal level. Interferon alpha $2 \mathrm{a}$, in $\mathrm{BD}$ has proven to reduce the duration and the pain of $\mathrm{OA}$ and the frequency of GU and papulopustular lesion, as well as erythema nodosumlike lesion, compared to placebo in a randomized placebocontrolled and double-blind study [57]. Similar results were found in 7 open studies [58-64]. In two previous reviews, the author highlighted that a treatment period of 2 to 4 months is at least necessary to obtain the highest effectiveness and declared a trend to disease relapse immediately or up to 7 months after treatment discontinuation [65] and rapidly responded after reinstitution of INF-alpha treatment [66]. An initially high dose (9 million units 3 times per week) for 3 months and then a low maintenance dose ( 3 million units 3 times per week) are recommended [53].

2.1.10. Anti-CD 52. Alemtuzumab is a humanized immunoglobulin G1 monoclonal antibody that targets CD 52, 







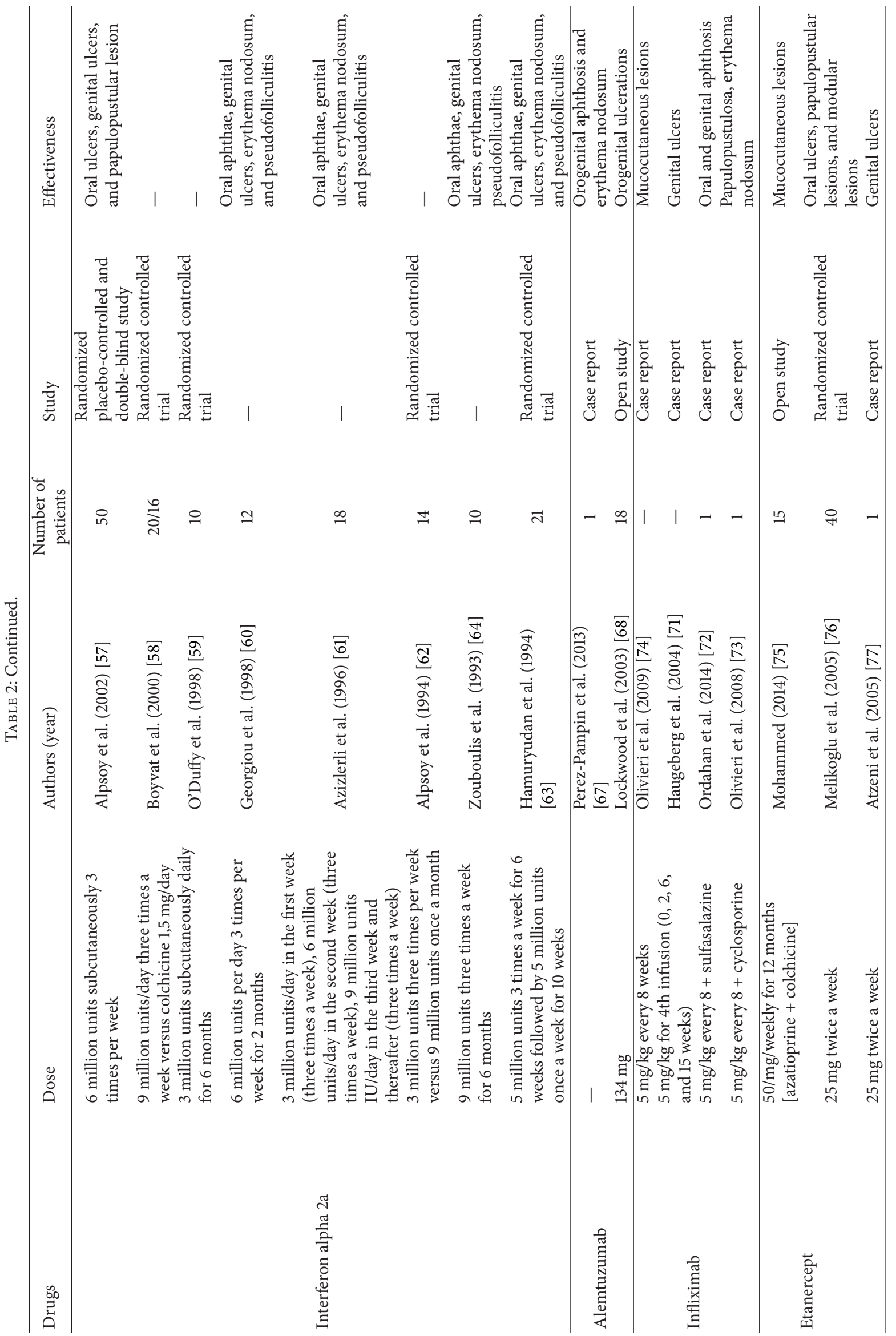




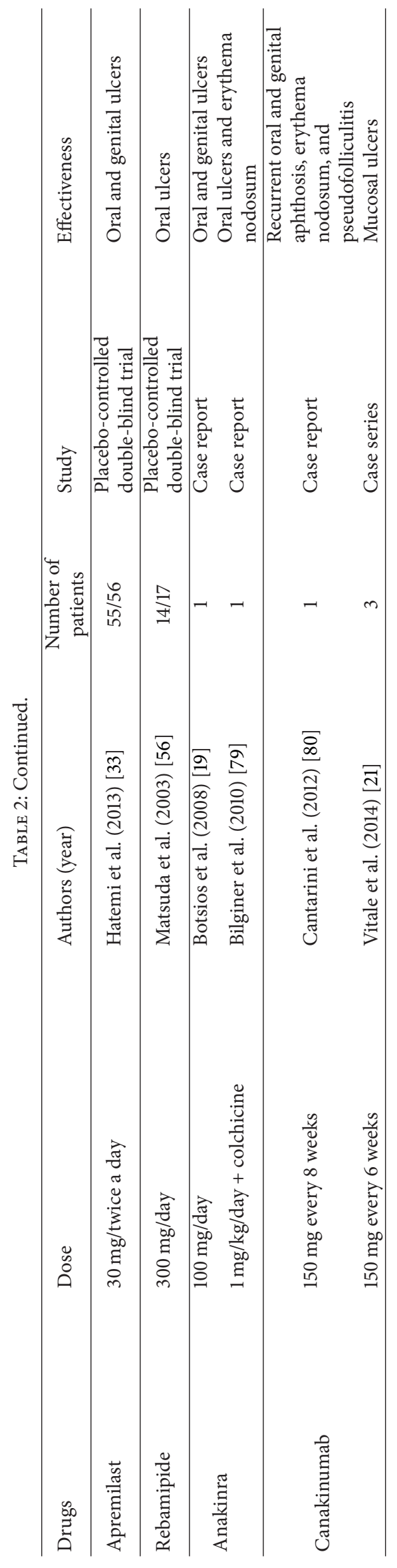


a glicosilate antigen that is present on lymphocytes and macrophages. Its main effect is T-cell depletion. In a case report, an 18-year-old woman with polyarthralgias, orogenital aphthosis, and erythema nodosum resisted conventional immunosuppressive therapy, describing a long lasting remission after the sixth subcutaneous administration [67]. In an open trial, 18 patients with orogenital ulcerations, ocular involvement, and neurological involvement, treated with Alemtuzumab (134 mg), in 6 months in $72 \%$ reached a complete remission and the daily dose of prednisolone was reduced; therapy was discontinued in 33\% for stable remission. The hypothyroidism development was the most common adverse effect recorded [68].

2.2. Current Treatment Option. In the last decade, the good efficacy of biotechnological drugs in the treatment of resistant mucocutaneous lesions has been demonstrated in several published works. In particular, the use of TNF-alpha inhibitors and IL-1 inhibitors has been described to improve these lesions.

Cytokines produced by $\mathrm{T}$ helper cells, including TNFalpha are described to play an important role in the molecular genesis of $\mathrm{BD}$ [69]. Higher soluble TNF-alpha receptors and TNF-alpha sera levels are found in active BD, with their spontaneous secretion by monocytes [70]. This finding supports the possible effective use of anti-TNF-alpha therapy in $\mathrm{BD}$.

2.2.1. Anti-TNF- $\alpha$ Inhibitors. In two clinical cases, patients with genital ulcers resistant to azathioprine and prednisone therapy, treated with infliximab $(5 \mathrm{mg} / \mathrm{kg}$ for a total of 4 infusion) reached a complete remission of the lesion [71, 72]. Hence, infliximab seems to produce good and long-lasting remission of mucocutaneous lesion, after its discontinuation at the 13th infusion as described in two clinical cases in which the patients were treated with infliximab, respectively, in association with azathioprine $(0.7 \mathrm{mg} / \mathrm{kg} /$ day $)$ and cyclosporine (3 mg/kg/day) [73, 74].

In an open study, the researchers described a good therapeutic response in patients with refractory mucocutaneous lesions, after 12 months of etanercept (50 mg/wk) therapy in addition to conventional immunosuppressive drug (azathioprine and colchicine) with a reduction of oral prednisolone [75]. In a randomized controlled trial (RCT) the effectiveness of etanercept in suppressing most of the mucocutaneous manifestations, such as the oral ulcers, the papulopustular lesions and nodular lesions has been demonstrated, and a lower probability of recurrence of oral ulcers has been described; the genital ulcers do not seem to improve after the treatment [76]. The improvement of genital ulcers after etanercept treatment ( $25 \mathrm{mg}$ twice week) is described in a case report [77].

2.2.2. Interleukin-1 Inhibitors. Recent studies have explained the role of different chemokines in cellular and molecular pathophysiology of BD [7], and, in particular, interleukin1 (IL-1) cytokine family is described to play a complex network of minor proinflammatory mediators and subsequent expression of integrins on leukocytes and endothelial cells, with many influences on the inflammatory response [78]. IL-1 has been recently described as a mediator of BD. This innovative concept introduces the identification of new potential targets for biological therapy [6]. Lately, the recombinant human IL-1 receptor antagonist (anakinra), the human immunoglobulin G1 (IgG1) anti-IL-1 beta monoclonal antibody (canakinumab), and the recombinant humanized anti-IL-1 beta antibody (gevokizumab) are proven to be partially useful in the treatment of $\mathrm{BD}$, while appearing to be more effective in ocular involvement [22]. However, with regard to the mucocutaneous lesions, good responses to anakinra have been reported in a patient with oral and genital ulcers resistant to conventional therapy [19] and in a teenager with aphthous lesions and cutaneous lesions unresponsive to traditional treatments [79]. In a case report and in a case series, canakinumab has proved to be successfully used in oral and genital aphthosis, skin lesions, and granuloma annulare $[21,80]$.

2.2.3. Phosphodiesterase 4 Inhibitors. Finally, apremilast, an inhibitor of phosphodiesterase 4 (PDE), a drug approved for psoriasis and psoriatic arthritis, seems to be a good alternative treatment in $\mathrm{BD}$. In a phase II randomized, placebocontrolled, double-blind study, the apremilast is observed to be effective in the treatment of oral ulcers and in treating genital ulcers [33].

\section{Conclusions}

$\mathrm{BD}$ is a complex syndrome, characterized by several clinical manifestations with usually frequent relapses. The mucocutaneous lesions represent nagging and typical manifestations in $\mathrm{BD}$, and their treatment management is usually driven by codominant clinical involvements, such as eyes and gastrointestinal and neurological involvement, or by the subject comorbidity. Although the traditional immunosuppressive drugs, as colchicine, corticosteroids, and azathioprine, are generally effective, several treatment failures, with severe and frequent relapses, troubled the course of the disease. In the last years, new pathogenetic hypothesis supported the use of new biotechnological drugs, as IL-1 inhibitors and $\mathrm{TNF} \alpha$ inhibitors, in the treatment of BD. Many clinical trials, open studies, and clinical case reports described their efficacy in the treatment of severe mucocutaneous manifestations. Further scientific demonstrations on large scale are necessary to prove their effects on reducing the frequency of mucocutaneous manifestations and on maintaining longterm effects. Several new drugs are under clinical study, but no data are reported yet. A wider drug range, with less adverse events risks, may provide alternative treatment tools for the clinicians, useful in nonresponding patients or in case of adverse events. The main unmet need in the overall management of $\mathrm{BD}$ is the lack of a specific treatment to target strategy; therefore, despite several available drugs, the treatment strategy of BD patients is still tailored according to the severity and type of organ involvement. The main goal of 
therapy in patients with $\mathrm{BD}$ is to induce and maintain disease remission and improve quality of life; in this regard, biologics are rapidly becoming effective alternatives to conventional treatments, also in mucocutaneous lesions. Since OA and $\mathrm{GU}$ represent relevant threats for quality of life impairment, biological drugs are recommended in mucocutaneous involvement, mainly when traditional drugs miss the mark.

\section{Conflict of Interests}

The authors declare that they have no conflict of interests regarding the publication of this paper.

\section{Authors' Contribution}

Cinzia Rotondo and Giuseppe Lopalco equally contributed to the work.

\section{References}

[1] H. Direskeneli, "Autoimmunity vs autoinflammation in Behcet's disease: do we oversimplify a complex disorder?" Rheumatology, vol. 45, no. 12, pp. 1461-1465, 2006.

[2] A. A. de Jesus and R. Goldbach-Mansky, "Monogenic autoinflammatory diseases: concept and clinical manifestations," Clinical Immunology, vol. 147, no. 3, pp. 155-174, 2013.

[3] I. Muscari, F. Iacoponi, L. Cantarini et al., "The diagnostic evaluation of patients with potential adult-onset autoinflammatory disorders: our experience and review of the literature," Autoimmunity Reviews, vol. 12, no. 1, pp. 10-13, 2012.

[4] G. Hatemi, Y. Yazici, and H. Yazici, "Behçet's syndrome," Rheumatic Disease Clinics of North America, vol. 39, no. 2, pp. 245261, 2013.

[5] A. Gül, "Behçet's disease as an autoinflammatory disorder," Current Drug Targets: Inflammation and Allergy, vol. 4, no. 1, pp. 81-83, 2005.

[6] L. Cantarini, G. Lopalco, F. Caso et al., "Effectiveness and tuberculosis-related safety profile of interleukin-1 blocking agents in the management of Behçet's disease," Autoimmunity Reviews, vol. 14, no. 1, pp. 1-9, 2015.

[7] G. Emmi, E. Silvestri, D. Squatrito et al., "Behçet's syndrome pathophysiology and potential therapeutic targets," Internal and Emergency Medicine, vol. 9, no. 3, pp. 257-265, 2014.

[8] H. Direskeneli, H. Fujita, and C. A. Akdis, "Regulation of TH17 and regulatory T cells in patients with Behçet disease," Journal of Allergy and Clinical Immunology, vol. 128, no. 3, pp. 665-666, 2011.

[9] C. Mendoza-Pinto, M. García-Carrasco, M. JiménezHernández et al., "Etiopathogenesis of Behcet's disease," Autoimmunity Reviews, vol. 9, no. 4, pp. 241-245, 2010.

[10] F. Caso, L. Costa, D. Rigante et al., "Biological treatments in Behçet's disease: beyond anti-TNF therapy," Mediators of Inflammation, vol. 2014, Article ID 107421, 14 pages, 2014.

[11] M. P. de Chambrun, B. Wechsler, G. Geri, P. Cacoub, and D. Saadoun, "New insights into the pathogenesis of Behçet's disease," Autoimmunity Reviews, vol. 11, no. 10, pp. 687-698, 2012.

[12] Z. Y. Zhou, S. L. Chen, N. Shen, and Y. Lu, "Cytokines and Behcet's disease," Autoimmunity Reviews, vol. 11, no. 10, pp. 699704, 2012.
[13] J. L. Mege, N. Dilsen, V. Sanguedolce et al., "Overproduction of monocyte derived tumor necrosis factor $\alpha$, interleukin (IL) 6 , IL-8 and increased neutrophil superoxide generation in Behcet's disease. A comparative study with familial Mediterranean fever and healthy subjects," Journal of Rheumatology, vol. 20, no. 9, pp. 1544-1549, 1993.

[14] A. F. de Vos, M. A. C. van Haren, C. Verhagen, R. Hoekzema, and A. Kijlstra, "Kinetics of intraocular tumor necrosis factor and interleukin-6 in endotoxin-induced uveitis in the rat," Investigative Ophthalmology \& Visual Science, vol. 35, no. 3, pp. 1100-1106, 1994.

[15] S. Hirohata, H. Kikuchi, T. Sawada et al., "Clinical characteristics of neuro-Behcet's disease in Japan: a multicenter retrospective analysis," Modern Rheumatology, vol. 22, no. 3, pp. 405-413, 2012.

[16] K. Hamzaoui, M. Hamza, and K. Ayed, "Production of TNF- $\alpha$ and IL-1 in active Behcet's disease," The Journal of Rheumatology, vol. 17, no. 10, pp. 1428-1429, 1990.

[17] S. Pay, H. Erdem, A. Pekel et al., "Synovial proinflammatory cytokines and their correlation with matrix metalloproteinase- 3 expression in Behçet's disease. Does interleukin- $1 \beta$ play a major role in Behçet's synovitis?" Rheumatology International, vol. 26, no. 7, pp. 608-613, 2006.

[18] M. Mesquida, B. Molins, V. Llorenç et al., "Current and future treatments for Behçet's uveitis: road to remission," International Ophthalmology, vol. 34, no. 2, pp. 365-381, 2014.

[19] C. Botsios, P. Sfriso, A. Furlan, L. Punzi, and C. A. Dinarello, "Resistant Behçet disease responsive to anakinra," Annals of Internal Medicine, vol. 149, no. 4, pp. 284-286, 2008.

[20] L. Cantarini, A. Vitale, P. Scalini et al., "Anakinra treatment in drug-resistant Behcet's disease: a case series," Clinical Rheumatology, 2013.

[21] A. Vitale, D. Rigante, F. Caso et al., "Inhibition of interleukin1 by canakinumab as a successful mono-drug strategy for the treatment of refractory Behçet's disease: a case series," Dermatology, vol. 228, no. 3, pp. 211-214, 2014.

[22] A. Gül, I. Tugal-Tutkun, C. A. Dinarello et al., "Interleukin-1 $\beta$ regulating antibody XOMA 052 (gevokizumab) in the treatment of acute exacerbations of resistant uveitis of Behçet's disease: an open-label pilot study," Annals of the Rheumatic Diseases, vol. 71, no. 4, pp. 563-566, 2012.

[23] L. Cantarini, I. Tinazzi, P. Caramaschi, F. Bellisai, A. Brogna, and M. Galeazzi, "Safety and efficacy of etanercept in children with juvenile-onset Behçets disease," International Journal of Immunopathology and Pharmacology, vol. 22, no. 2, pp. 551-555, 2009.

[24] R. Talarico, L. Cantarini, A. d'Ascanio et al., "Development of de novo major involvement during follow-up in Behçet's syndrome," Clinical Rheumatology, 2015.

[25] K. Tascilar, M. Melikoglu, S. Ugurlu, N. Sut, E. Caglar, and H. Yazici, "Vascular involvement in Behçet's syndrome: a retrospective analysis of associations and the time course," Rheumatology, vol. 53, no. 11, pp. 2018-2022, 2014.

[26] G. Akman-Demir, P. Serdaroglu, and B. Tasçi, “Clinical patterns of neurological involvement in Behcet's disease: evaluation of 200 patients," Brain, vol. 122, no. 11, pp. 2171-2181, 1999.

[27] M.-H. Houman, S. Bellakhal, T. B. Salem et al., "Characteristics of neurological manifestations of Behçet's disease: a retrospective monocentric study in Tunisia," Clinical Neurology and Neurosurgery, vol. 115, no. 10, pp. 2015-2018, 2013.

[28] I. Koné-Paut, M. Darce-Bello, F. Shahram et al., "Registries in rheumatological and musculoskeletal conditions. Paediatric 
Behçet's disease: an international cohort study of 110 patients. One-year follow-up data," Rheumatology, vol. 50, no. 1, pp. 184188, 2011.

[29] E. Alpsoy, C. C. Zouboulis, and G. E. Ehrlich, "Mucocutaneous lesions of Behçet's disease," Yonsei Medical Journal, vol. 48, no. 4, pp. 573-585, 2007.

[30] G. E. Ehrlich, "Behçet's disease: an update," Comprehensive Therapy, vol. 25, no. 4, pp. 216-220, 1999.

[31] H. K. Chang and K. S. Cheon, "The clinical significance of a pathergy reaction in patients with Behçet's disease," Journal of Korean Medical Science, vol. 17, no. 3, pp. 371-374, 2002.

[32] G. Hatemi, A. Silman, D. Bang et al., "EULAR recommendations for the management of Behçet disease," Annals of the Rheumatic Diseases, vol. 67, no. 12, pp. 1656-1662, 2008.

[33] G. Hatemi, M. Melikoglu, R. Tunc et al., "Apremilast for the treatment of Behçet's syndrome: a phase II randomized, placebo-controlled, double-blind study," Arthritis \& Rheumatism, vol. 65, no. 10, supplement, p. S322, 2013.

[34] H. Yazici, H. Pazarli, C. G. Barnes et al., "A controlled trial OF azathioprine in Behçet's syndrome," The New England Journal of Medicine, vol. 322, no. 5, pp. 281-285, 1990.

[35] E. Aktulga, M. Altac, A. Muftuoglu et al., "A double blind study of colchicine in Behcet's disease," Haematologica, vol. 65, no. 3, pp. 399-402, 1980.

[36] S. Yurdakul, C. Mat, Y. Tuzun et al., "A double-blind trial of colchicine in Behçet's syndrome," Arthritis and Rheumatism, vol. 44, no. 11, pp. 2686-2692, 2001.

[37] F. Davatchi, B. S. Abdollahi, A. T. Banihashemi et al., "Colchicine versus placebo in Behçet's disease: randomized, doubleblind, controlled crossover trial," Modern Rheumatology, vol. 19, no. 5, pp. 542-549, 2009.

[38] M. Çalgüneri, I. Ertenli, S. Kiraz, M. Erman, and I. Çelik, "Effect of prophylactic benzathine penicillin on mucocutaneous symptoms of Behçet's disease," Dermatology, vol. 192, no. 2, pp. 125-128, 1996.

[39] M. M. Al-Waiz, K. E. Sharquie, M. H. A-Qaissi, and R. K. Hayani, "Colchicine and benzathine penicillin in the treatment of Behçet disease: a case comparative study," Dermatology Online Journal, vol. 11, no. 3, article 3, 2005.

[40] M.-T. Labro, "Immunological effects of macrolides," Current Opinion in Infectious Diseases, vol. 11, no. 6, pp. 681-688, 1998.

[41] E. Isogai, S. Ohno, S. Kotake et al., "Chemiluminescence of neutrophils from patients with Behçet's disease and its correlation with an increased proportion of uncommon serotypes of Streptococcus sanguis in the oral flora," Archives of Oral Biology, vol. 35, no. 1, pp. 43-48, 1990.

[42] G. Mumcu, T. Ergun, Y. Elbir et al., "Clinical and immunological effects of azithromycin in Behçet's disease," Journal of Oral Pathology and Medicine, vol. 34, no. 1, pp. 13-16, 2005.

[43] G. Mumcu, N. Inanç, F. T. Özdemir et al., "Effects of azithromycin on intracellular cytokine responses and mucocutaneous manifestations in Behçet's disease," International Journal of Dermatology, vol. 52, no. 12, pp. 1561-1566, 2013.

[44] F. Kaneko, N. Oyama, and A. Nishibu, "Streptococcal infection in the pathogenesis of Behcet's disease and clinical effects of minocycline on the disease symptoms," Yonsei Medical Journal, vol. 38, no. 6, pp. 444-454, 1997.

[45] V. Hamuryudan, C. Mat, S. Saip et al., "Thalidomide in the treatment of the mucocutaneous lesions of the Behcet syndrome: a randomized, double-blind, placebo-controlled trial," Annals of Internal Medicine, vol. 128, no. 6, pp. 443-450, 1998.
[46] B. De Wazières, H. Gil, N. Magy, S. Berthier, D. A. Vuitton, and J. L. Dupond, "Treatment of recurrent oro-genital ulceration with low dose of thalidomide. Pilot study in 17 patients," La Revue de Médecine Interne, vol. 20, no. 7, pp. 567-570, 1999.

[47] J. M. M. Gardner-Medwin, N. J. Smith, and R. J. Powell, "Clinical experience with thalidomide in the management of severe oral and genital ulceration in conditions such as Behcet's disease: use of neurophysiological studies to detect thalidomide neuropathy," Annals of the Rheumatic Diseases, vol. 53, no. 12, pp. 828-832, 1994.

[48] T. Saylan and I. Saltik, "Thalidomide in the treatment of Behcet's syndrome," Archives of Dermatology, vol. 118, no. 8, p. 536, 1982.

[49] D. M. Hamza, "Treatment of Behçet's disease with thalidomide," Clinical Rheumatology, vol. 5, no. 3, pp. 365-371, 1986.

[50] K. Masuda, A. Urayama, M. Kogure, A. Nakajima, K. Nakae, and G. Inaba, "Double-masked trial of cyclosporin versus colchicine and long-term open study of cyclosporin in Behçet's disease," The Lancet, vol. 333, no. 8647, pp. 1093-1096, 1989.

[51] S. Assaad-Khalil, "Low-dose cyclosporin in Behçet's disease: follow-up controlled study with emphasis on extraocular manifestations and neuro-Behçet's disease," in Behçet's Disease: Basic and Clinical Aspects, pp. 603-612, CRC Press, Boca Raton, Fla, USA, 1991.

[52] O. Avci, N. Gurler, and A. T. Gunes, "Efficacy of cyclosporine on mucocutaneons manifestations of Behçet's disease," Journal of the American Academy of Dermatology, vol. 36, no. 5, pp. 796797, 1997.

[53] P. Lin and G. Liang, "Behçet disease: recommendation for clinical management of mucocutaneous lesions," Journal of Clinical Rheumatology, vol. 12, no. 6, pp. 282-286, 2006.

[54] K. E. Sharquie, "Suppression of Behcet's disease with dapsone," British Journal of Dermatology, vol. 110, no. 4, pp. 493-494, 1984.

[55] K. E. Sharquie, R. A. Najim, and A. R. Abu-Raghif, "Dapsone in Behçet's disease: a double-blind, placebo-controlled, cross-over study," Journal of Dermatology, vol. 29, no. 5, pp. 267-279, 2002.

[56] T. Matsuda, S. Ohno, S. Hirohata et al., "Efficacy of rebamipide as adjunctive therapy in the treatment of recurrent oral aphthous ulcers in patients with Behçet's disease: a randomised, double-blind, placebo-controlled study," Drugs in R and D, vol. 4, no. 1, pp. 19-28, 2003.

[57] E. Alpsoy, C. Durusoy, E. Yilmaz et al., "Interferon alfa-2a in the treatment of Behçet disease: a randomized placebo-controlled and double-blind study," Archives of Dermatology, vol. 138, no. 4, pp. 467-471, 2002.

[58] A. Boyvat, C. Şişman-Solak, and A. Gürler, "Long-term effects of interferon alpha 2A treatment in Behcet's disease," Dermatology, vol. 201, no. 1, pp. 40-43, 2000.

[59] J. D. O’Duffy, K. Calamia, S. Cohen et al., "Interferon- $\alpha$ treatment of Behcet's disease," The Journal of Rheumatology, vol. 25, no. 10, pp. 1938-1944, 1998.

[60] S. Georgiou, A. Monastirli, E. Pasmatzi, S. Gartaganis, G. Goerz, and D. Tsambaos, "Efficacy and safety of systemic recombinant interferon-alpha in Behçet's disease," Journal of Internal Medicine, vol. 243, no. 5, pp. 367-372, 1998.

[61] G. Azizlerli, R. Sarica, A. Köse et al., "Interferon alfa-2a in the treatment of Behçet's disease," Dermatology, vol. 192, no. 3, pp. 239-241, 1996.

[62] E. Alpsoy, E. Yilmaz, and E. Basaran, "Interferon therapy for Behçet's disease," Journal of the American Academy of Dermatology, vol. 31, no. 4, pp. 617-619, 1994. 
[63] V. Hamuryudan, F. Moral, S. Yurdakul et al., "Systemic interferon alpha $2 \mathrm{~b}$ treatment in Behçet's syndrome," Journal of Rheumatology, vol. 21, no. 6, pp. 1098-1100, 1994.

[64] C. Zouboulis, R. Treudler, and C. Orfanos, "AdamantiadesBehçet's disease. Therapeutic administration of systemic recombinant interferon- $\alpha$-2a," Der Hautarzt, vol. 44, pp. 440-445, 1993.

[65] C. C. Zouboulis and C. E. Orfanos, "Treatment of Adamantiades-Behçet disease with systemic interferon alfa," Archives of Dermatology, vol. 134, no. 8, pp. 1010-1016, 1998.

[66] I. Kötter, I. Günaydin, M. Zierhut, and N. Stübiger, “The use of interferon $\alpha$ in Behçet disease: review of the literature," Seminars in Arthritis and Rheumatism, vol. 33, no. 5, pp. 320-335, 2004.

[67] E. Perez-Pampin, J. Campos-Franco, J. Blanco, and A. Mera, "Remission induction in a case of refractory behcet disease with alemtuzumab," Journal of Clinical Rheumatology, vol. 19, no. 2, pp. 101-103, 2013.

[68] C. M. Lockwood, G. Hale, H. Waldman, and D. R. W. Jayne, "Remission induction in Behçet's disease following lymphocyte depletion by the anti-CD52 antibody CAMPATH 1-H," Rheumatology, vol. 42, no. 12, pp. 1539-1544, 2003.

[69] P. P. Sfikakis, "Behçet's disease: a new target for anti-tumour necrosis factor treatment," Annals of the Rheumatic Diseases, vol. 61, no. 2, pp. ii51-ii53, 2002.

[70] N. Sayinalp, O. I. Özcebe, O. Özdemir, I. C. Haznedaroglu, S. Dündar, and Ş. Kirazli, "Cytokines in Behçet's disease," Journal of Rheumatology, vol. 23, no. 2, pp. 321-322, 1996.

[71] G. Haugeberg, M. Velken, and V. Johnsen, "Successful treatment of genital ulcers with infliximab in Behçet's disease," Annals of the Rheumatic Diseases, vol. 63, no. 6, pp. 744-745, 2004.

[72] B. Ordahan, A. Y. Karahan, S. C. Doğan, L. Tekin, S. Küçüksaraç, and E. Salbaş, "Infliximab treatment in co-existing behcet's disease and ankylosing spondylitis case presentation," Journal of Rheumatology and Orthopedics, vol. 1, 2014.

[73] I. Olivieri, L. Latanza, S. Siringo, G. Peruz, and V. Di Iorio, "Successful treatment of severe Behçet's disease with infliximab in an Italian olympic athlete," The Journal of Rheumatology, vol. 35, no. 5, pp. 930-932, 2008.

[74] I. Olivieri, A. Padula, P. Leccese, S. D’Angelo, and V. Giasi, "Long-lasting remission of severe Behçet's disease after the end of infliximab therapy," Journal of Rheumatology, vol. 36, no. 4, article 855, 2009.

[75] R. Mohammed, "Etanercept therapy in Behçet's disease," Zeitschrift für Rheumatologie, vol. 73, no. 7, pp. 650-656, 2014.

[76] M. Melikoglu, I. Fresko, C. Mat et al., "Short-term trial of etanercept in Behçet's disease: a double blind, placebo controlled study," Journal of Rheumatology, vol. 32, no. 1, pp. 98-105, 2005.

[77] F. Atzeni, P. Sarzi-Puttini, F. Capsoni, M. Mecchia, M. G. Marrazza, and M. Carrabba, "Successful treatment of resistant Behçet's disease with etanercept," Clinical and Experimental Rheumatology, vol. 23, no. 5, p. 729, 2005.

[78] C. A. Dinarello, "Interleukin-1 in the pathogenesis and treatment of inflammatory diseases," Blood, vol. 117, no. 14, pp. 37203732, 2011.

[79] Y. Bilginer, N. A. Ayaz, and S. Ozen, "Anti-IL-1 treatment for secondary amyloidosis in an adolescent with FMF and Behçet's disease," Clinical Rheumatology, vol. 29, no. 2, pp. 209-210, 2010.

[80] L. Cantarini, A. Vitale, M. Borri, M. Galeazzi, and R. Franceschini, "Successful use of canakinumab in a patient with resistant Behçet's disease," Clinical and Experimental Rheumatology, vol. 30, no. 3, supplement 72, p. S115, 2012. 


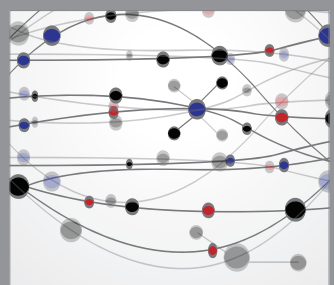

The Scientific World Journal
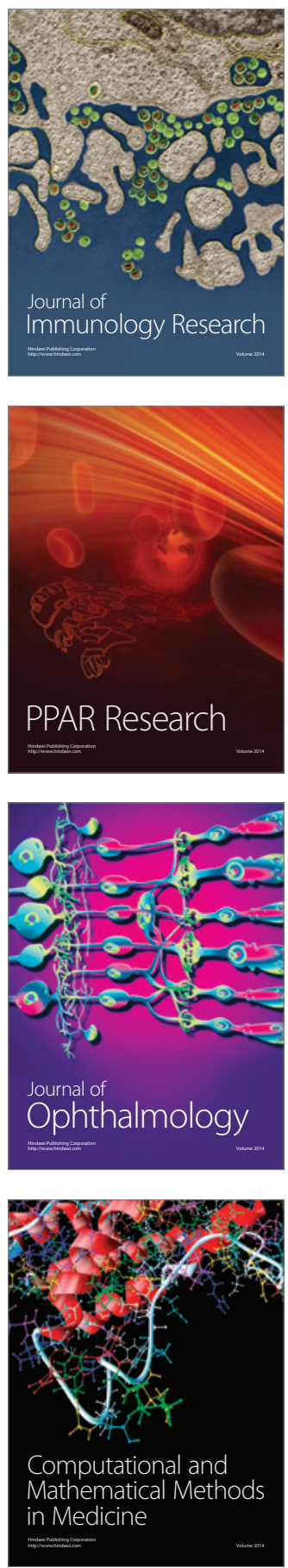

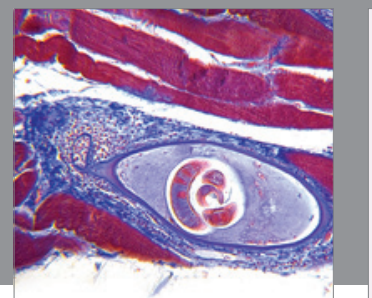

Gastroenterology

Research and Practice
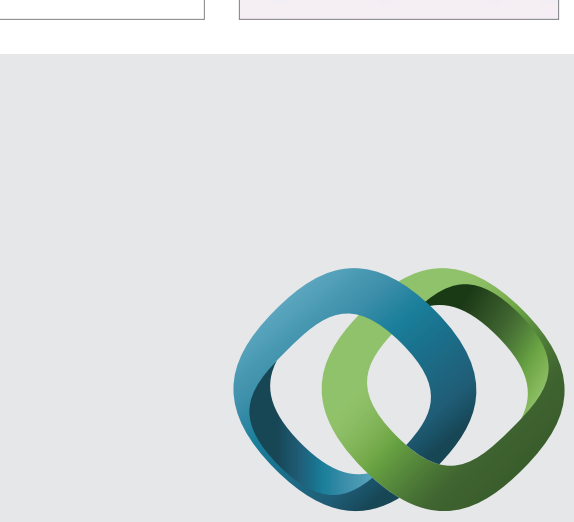

\section{Hindawi}

Submit your manuscripts at

http://www.hindawi.com
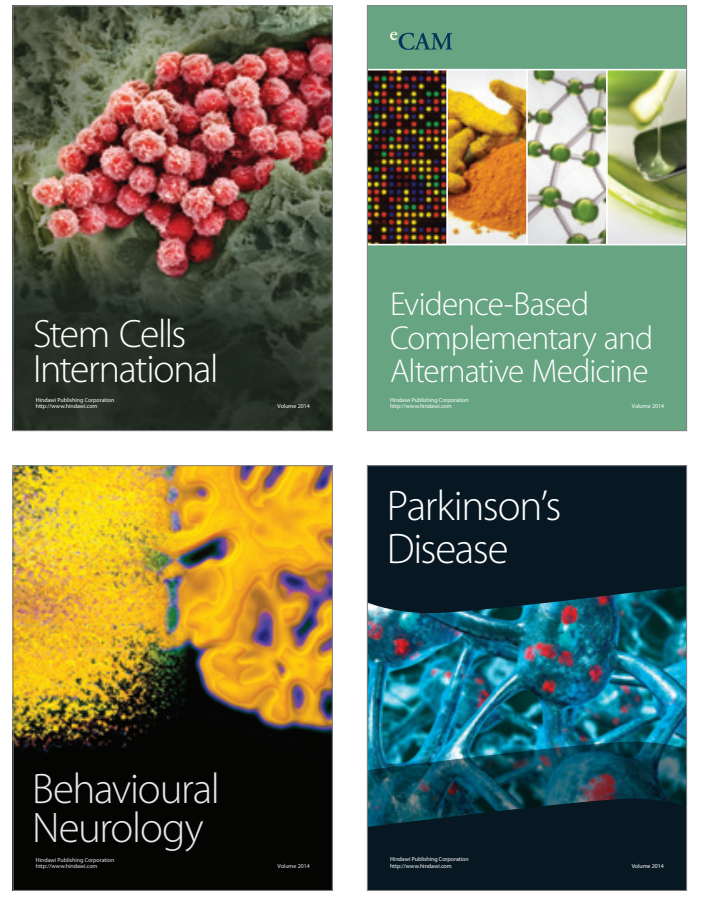
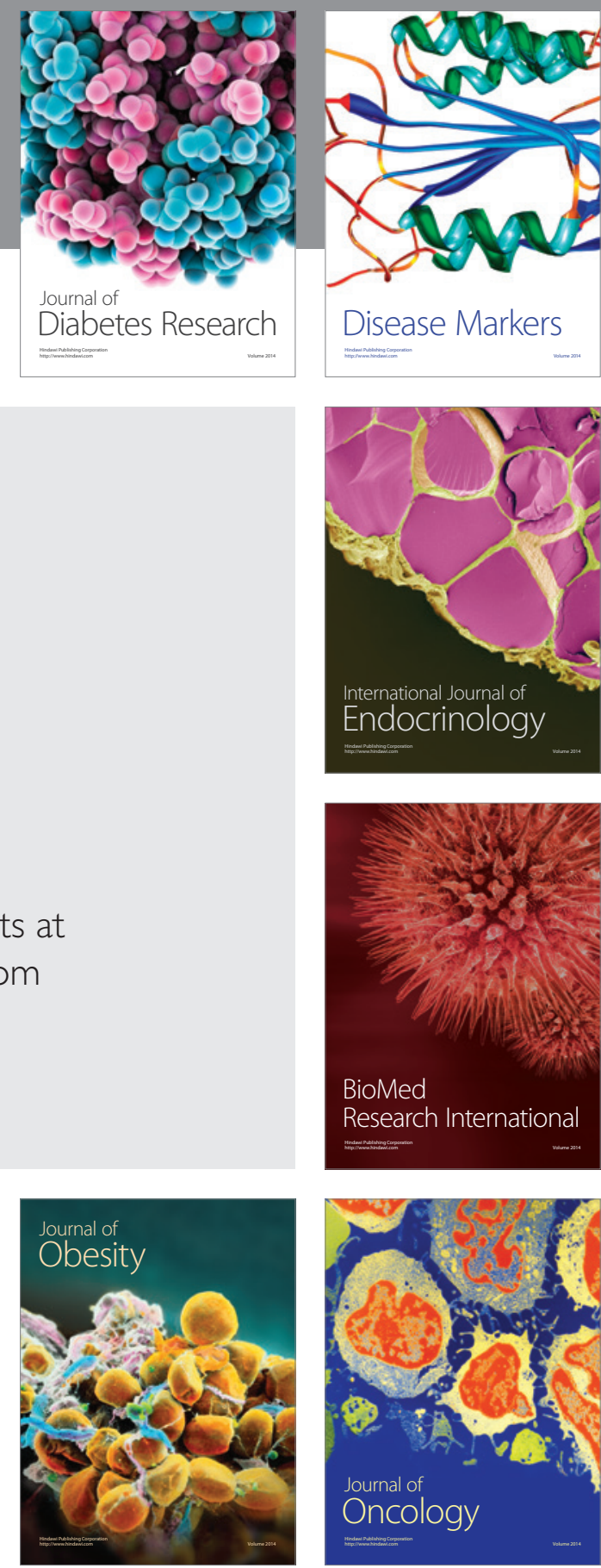

Disease Markers
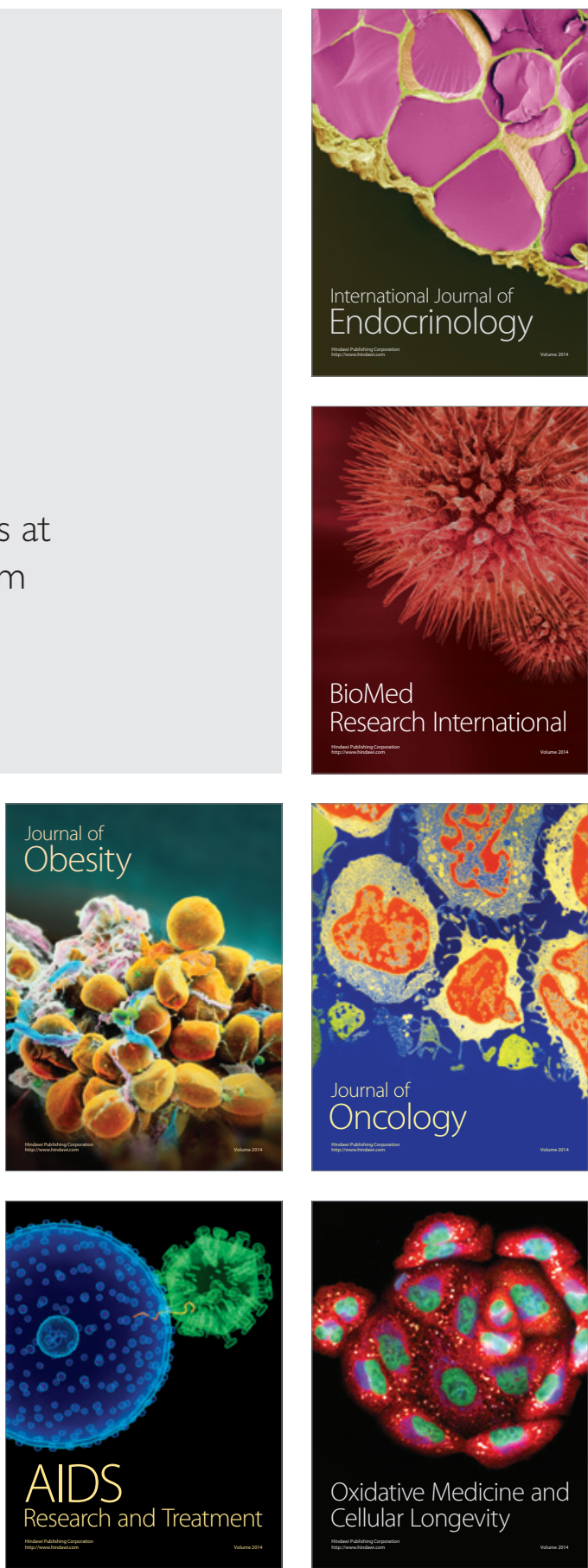